\title{
Familial spinocerebellar degeneration as an expression of adrenoleukodystrophy
}

\author{
TAKURO KOBAYASHI, ${ }^{*}$ SHOSAKU NODA, $\dagger$ HIROTOSHI UMEZAKI, $\dagger$ \\ IKUO GOTO,* SATOSHI SUZUKI,* TETSUO KITAGUCHI,* \\ YOSHIGORO KUROIWA*
}

From the Department of Neurology, ${ }^{*}$ Neurological Institute, Faculty of Medicine, Kyushu University, Fukuoka and Department of Neurology, $\dagger$ Kyushu Koseinenkin Hospital, Kitakyushu, Japan

SUMMARY A family with adrenoleukodystrophy and clinical manifestations of spinocerebellar degeneration was studied. Two adult male first cousins showed progressive limb and truncal ataxia, slurred speech and spasticity of the extremities. Brain CT scans demonstrated atrophy of the pons and cerebellum, in both cases. Very long chain fatty acids in plasma and erythrocyte membranes were elevated in the affected patients and intermediately increased in an aunt and the mother of one patient, thereby indicating homozygotes and carriers of adrenoleukodystrophy, respectively. This unusual type of adrenoleukodystrophy seems to be transmitted as an X-linked recessive trait.

Adrenoleukodystrophy and adrenomyeloneuropathy are X-linked recessive disorders characterised by adrenal insufficiency and demyelination in the central and peripheral nervous systems. ${ }^{1-3}$ Biochemically, very long chain fatty acids (VLCFA) accumulate in the tissues and body fluids. ${ }^{45}$ We describe here a family with adrenoleukodystrophy and clinical manifestations of spinocerebellar degeneration, attributed to an X-linked recessive inheritance, based on an analysis of VLCFA.

Case reports (pedigree fig)

Case 1 (III-9)

A Japanese man had been well until age 27 years, and physical and mental developments were normal. At age 27 , he noticed dysarthria and unsteadiness in walking, and these symptoms were progressive. On admission, he was alert and oriented. Recent and remote memory seemed intact. He would calculate well, but sometimes could not understand simple questions. Total IQ measured by Wechsler Adult

Address for reprint requests: Takuro Kobayashi, MD, Department of Neurology, Neurological Institute, Faculty of Medicine, Kyushu University 60, 3-1-1- Maidashi, Higashi-ku, Fukuoka 812, Japan.

Received 10 December 1985 and in revised form 26 February 1986. Accepted 1 March 1986
Intelligence Scale was 65 . There was dark pigmentation on his skin, gums and lower half of the sclera. Visual and hearing acuities were normal. Ocular movements were smooth, without nystagmus. His speech was markedly slurred. Extremities were dysmetric on finger-nose and knee-heel tests. Bilateral lower extremities were moderately spastic and deep tendon reflexes were exaggerated with positive bilateral Babinski's sign. His gait was markedly ataxic and somewhat spastic. He could hardly walk without support, yet sensory impairment was not demonstrated.

The plasma ACTH level was $20-25 \mathrm{pg} / \mathrm{ml}$ (normal 10-100). Plasma cortisol level responded well to ACTH stimulation $(6.3$ to $27.4 \mu \mathrm{g} / \mathrm{dl}, 30 \mathrm{~min}$ after $0.25 \mathrm{mg}$ of intravenous ACTH injection; (normal response $>$ double of basal level). Plasma FSH, aldosterone and testosterone levels were normal. An EEG revealed findings of occasional theta waves among the background activities. Motor nerve conduction velocity was $34.4 \mathrm{~m} / \mathrm{s}$ in the right peroneal nerve (normal 45-53) and sensory nerve conduction velocity was $28 \mathrm{~m} / \mathrm{s}$ in right sural nerve (normal 46-60). Brain CT scans demonstrated atrophy of the pons and cerebellum, but the cerebrum seemed to be intact.

Case 2 (III-2, a first cousin of case 1)

A man who first noticed an unsteady gait at age 22 

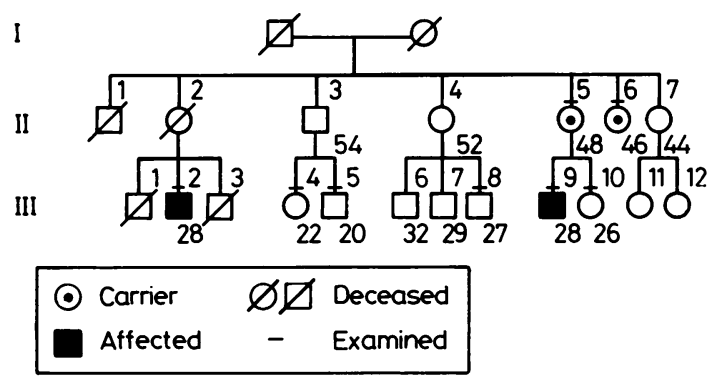

Fig 1 Family pedigree.

years. There was a gradual progression during 2 years, then ataxic speech occurred. At age 26, he complained of difficulty in walking downstairs. This state became progressively worse and he could not walk without support by the time he was 27 . On admission, he was well nourished and his skin was not pigmented. Neurological examination revealed a forced laughing but without dementia (IQ 98) and a marked scanning speech. Visual and hearing acuities were normal. Eye movements were full without nystagmus but saccadic and irregular movements were detected in the pursuit tests. Limb and truncal ataxia, spasticity and hyperreflexias in the four limbs, bilateral Babinski's sign and spastic-ataxic gait were all present.

Laboratory data revealed a normal urinary secretion of 17 ketosteroids and 17OHCS and normal plasma ACTH levels $(10 \mathrm{pg} / \mathrm{ml})$. Borderline response of plasma cortisol levels were demonstrated on the ACTH stimulation test (7.1 to $13.7 \mu \mathrm{g} / \mathrm{dl}, 1$ hour after injection). An EEG showed slightly excessive slowing in the background activities and occasional rhythmic theta waves. EMG and nerve conduction studies were normal. Brain CT scans showed an atrophy of the pons and cerebellum.

Clinical data on this patient have previously been reported. ${ }^{6}$ Three years after admission, he was confined to a wheel-chair. His memory and ability to calculate were intact.
Family members

Six members in the family (II-5, II-6, III-4, III-5, III-8 and III-10) proved to be neurologically normal.

\section{VLCFA levels}

VLCFA levels in the sphingomyelin of the plasma and erythrocyte membranes were measured, using highperformance liquid chromatography. ${ }^{7}$ Increased levels of VLCFA in both plasma and erythrocyte membranes were observed in cases 1 and 2 (table). II-5 and II-6 showed intermediate increase in VLCFA. Other members of the family were normal.

\section{Discussion}

While adrenomyeloneuropathy is a well-known variant of adrenoleukodystrophy, ${ }^{2}$ rarer forms have been reported; adrenoleukodystrophy with symptoms of Kluver-Bucy syndrome ${ }^{8}$ and adrenoleukodystrophy resembling brain tumour of the left hemisphere. ${ }^{9}$ Marsden et al ${ }^{10}$ reported an adrenoleukodystrophy patient presenting as spino-cerebellar degeneration. They did not report the VLCFA levels but the patient did have a positive family history of adrenoleukodystrophy. The patient had cerebellar signs as well as dementia, incontinence, epileptic seizures, optic atrophy and hypaesthesia in the legs with stocking-type distribution. Recently Ohno et al $^{11}$ also reported a sporadic case of adrenoleukodystrophy presenting as olivopontocerebellar atrophy.

From the clinical picture of slowly progressive limb and truncal ataxia and brain CT scans showing atrophy of the brainstem and cerebellum, the diagnosis of spinocerebellar degeneration was made in our patients. The case 1 patient was considered to have peripheral neuropathy, determined from studies on conduction velocity. In an analysis of VLCFA of the patients and their family members, the patients were considered to have adrenoleukodystrophy and their aunt and the mother of case 1 , as the carriers. This seems to be the first report of a family of adre-

Table Very long chain fatty acids of sphingomyelin in plasma and erythrocyte membranes

\begin{tabular}{|c|c|c|c|c|c|c|}
\hline & $\begin{array}{l}\text { Plasma } \\
\text { C24:0 }\end{array}$ & $C 25: 0$ & $C 26: 0$ & $\begin{array}{l}\text { Erythro } \\
\text { C24:0 }\end{array}$ & $\begin{array}{l}\text { anes } \\
\text { C25:0 }\end{array}$ & $C 26: 0$ \\
\hline $\begin{array}{l}\text { II-5 } \\
\text { II-6 } \\
\text { III-2 } \\
\text { III-4 } \\
\text { III-5 } \\
\text { III-8 } \\
\text { III-9 } \\
\text { III-10 } \\
\text { Control } \\
(\mathbf{n}=18)\end{array}$ & $\begin{array}{c}1.29 \\
0.96 \\
1.25 \\
0.57 \\
0.71 \\
0.76 \\
1.56 \\
0.58 \\
0.70 \\
\pm 0.06\end{array}$ & $\begin{array}{c}0.044 \\
0.028 \\
0.034 \\
0.011 \\
0.011 \\
0.013 \\
0.053 \\
0.012 \\
0.012 \\
\pm 0.003\end{array}$ & $\begin{array}{c}0.020 \\
0.011 \\
0.020 \\
0.004 \\
0.013 \\
0.011 \\
0.025 \\
0.006 \\
0.010 \\
\pm 0.002\end{array}$ & $\begin{array}{c}2.98 \\
2.32 \\
3.18 \\
2.42 \\
2.40 \\
2.33 \\
3.27 \\
2.56 \\
2.45 \\
\pm 0.21\end{array}$ & $\begin{array}{c}0.097 \\
0.058 \\
0.092 \\
0.050 \\
0.043 \\
0.038 \\
0.127 \\
0.066 \\
0.060 \\
\pm 0.012\end{array}$ & $\begin{array}{c}0.179 \\
0.134 \\
0.207 \\
0.091 \\
0.092 \\
0.084 \\
0.250 \\
0.111 \\
0.100 \\
\pm 0.015\end{array}$ \\
\hline
\end{tabular}

Values are expressed on the basis of C22:0. Control values are expressed as mean \pm SD. 
noleukodystrophy presenting as spinocerebellar degeneration. VLCFA analyses indicated that transmission was through an $\mathrm{X}$-linked recessive trait, the same as in cases of classical adrenoleukodystrophy and adrenomyeloneuropathy.

Necropsy data on two patients with adrenoleukodystrophy and cerebellar lesions have been reported. ${ }^{12} 13$ In both, there was demyelination of the white matter in the cerebellum and in the pons. Tateishi et al ${ }^{13}$ detected lesions in the cerebellar cortex, inferior olive and pontine nucleus, lesions which closely resembled typical ones seen in cases of olivopontocerebellar atrophy. The case 2 patient had no clinical signs of adrenal insufficiency and adrenal function tests were normal, in both cases. Some biochemically-confirmed adrenoleukodystrophy patients did have a normal adrenal function. ${ }^{5}$ Therefore, adrenoleukodystrophy should not be ruled out and VLCFA should be measured in patients with spinocerebellar degeneration, even in the absence of adrenal insufficiency, because treatment for the adrenoleukodystrophy may be feasible. ${ }^{14-17}$

These investigations were supported in part by Grant No. 84-11 from the National Centre of Nervous, Mental and Muscular Disorders (NCNMMD) of the Ministry of Health and Welfare, Japan and by a Grant-in-Aid from Special Research of Selected Intractable Neurological Disorders from the Ministry of Education, Science and Culture, Japan. We thank Professor $\mathbf{J}$ Tateishi for making available unpublished necropsy data and $M$ Ohara for comments on the manuscript.

\section{References}

1 Schaumburg HH, Powers JM, Raine CS, Suzuki K, Richardson EP. Adrenoleukodystrophy. A clinical and pathological study of 17 cases. Arch Neurol 1975;32:577-91.

2 Griffin JW, Goren E, Schaumburg HH, Engel WK, Loriaux L. Adrenomyeloneuropathy: A probable variant of adrenoleukodystrophy. I. Clinical and endocrinologic aspects. Neurology 1977;27:1107-13.

3 Schaumburg HH, Powers JM, Raine CS, et al. Adreno- myeloneuropathy: A probable variant of adrenoleukodystrophy. II. General pathologic, neuropathologic, and biochemical aspects. Neurology 1977;27:1114-9.

4 Igarashi M, Schaumburg HH, Powers JM, Kishimoto Y, Kolodny E, Suzuki K. Fatty acid abnormality in adrenoleukodystrophy. $J$ Neurochem 1976;26:851-60.

5 Moser HW, Moser AE, Singh I, O'Neill BP. Adrenoleukodystrophy: Survey of 303 cases: Biochemistry, diagnosis and therapy. Ann Neurol 1984;16:628-41.

6 Suzuki S, Kitaguchi T, Tabira T, Goto I, Kuroiwa Y. Adrenoleukodystrophy presenting as spinocerebellar degeneration. Rinsho Shinkeigaku 1983;23:678-82. (in Japanese)

7 Kobayashi T, Katayama M, Suzuki S, Tomoda H, Goto I, Kuroiwa Y. Adrenoleukodystrophy: detection of increased very long chain fatty acids by highperformance liquid chromatography. $J$ Neurol 1983;230:209-15.

8 Powers JM, Schaumburg HH, Gaffney CL. Kluver-Bucy syndrome caused by adrenoleukodystrophy. Neurology 1980;30:1131-2.

9 Case records of Massachusetts General Hospital. $N$ Engl J Med 1979;300:1037-45.

10 Marsden CD, Obeso JA, Lang AE. Adrenoleukomyeloneuropathy presenting as spinocerebellar degeneration. Neurology 1982;32:1031-2.

11 Ohno T, Tsuchida H, Fukuhara N, et al. Adrenoleukodystrophy: A clinical variant presenting as olivopontocerebellar atrophy. $J$ Neurol 1984;231:167-9.

12 Kuroda S, Hirano A, Yuasa S. Adrenoleukodystrophy. A cerebello-brainstem dominant case. Acta Neuropathol 1983;60:149-52.

13 Tateishi J, Sato Y, Suetsugu M, Takashiba T. Adrenoleukodystrophy with olivopontocerebellar atrophylike lesions. Clin Neuropathol 1986;5:34-9.

14 Brown III FR, Van Duyn MAS, Moser AB, et al. Adrenoleukodystrophy: Effects of dietary restriction of very long chain fatty acids and of administration of carnitine and clofibrate on clinical status and plasma fatty acids. Johns Hopkins Med J 1982;151:164-72.

15 Murphy JV, Marquardt KM, Moser HW, Van Duyn MA. Treatment of adrenoleukodystrophy by diet and plasmapheresis. Ann Neurol 1982;12:220.

16 Moser HW, Tutschka PJ, Brown III FR, et al. Bone marrow transplant in adrenoleukodystrophy. Neuro$\log y$ 1984;34:1410-7.

17 Suzuki S, Kobayashi T, Goto I, Kuroiwa Y. Dietary treatment of adrenoleukodystrophy. Neurology 1986; 36:104-6. 